Article

\title{
Immunonutritive Scoring for Patients with Hepatocellular Carcinoma Undergoing Transarterial Chemoembolization: Evaluation of the CALLY Index
}

\author{
Lukas Müller ${ }^{1}{ }^{\mathbb{D}}$, Felix Hahn ${ }^{1}$, Aline Mähringer-Kunz ${ }^{1}$, Fabian Stoehr ${ }^{1}$, Simon Johannes Gairing ${ }^{2}$, \\ Maurice Michel ${ }^{2}$, Friedrich Foerster ${ }^{2}$, Arndt Weinmann ${ }^{2}$, Peter Robert Galle ${ }^{2}$ (D) Jens Mittler ${ }^{3}$ (D), \\ Daniel Pinto dos Santos ${ }^{4}\left(\mathbb{D}\right.$, Michael Bernhard Pitton ${ }^{1}\left(\mathbb{D}\right.$, Christoph Düber $^{1}$ and Roman Kloeckner ${ }^{1, *(D)}$
}

Citation: Müller, L.; Hahn, F.; Mähringer-Kunz, A.; Stoehr, F.; Gairing, S.J.; Michel, M.; Foerster, F.; Weinmann, A.; Galle, P.R.; Mittler, J.; et al. Immunonutritive Scoring for Patients with Hepatocellular Carcinoma Undergoing Transarterial Chemoembolization: Evaluation of the CALLY Index. Cancers 2021, 13, 5018. https://doi.org/10.3390/ cancers13195018

Academic Editor: Xavier Verhelst

Received: 30 August 2021

Accepted: 5 October 2021

Published: 7 October 2021

Publisher's Note: MDPI stays neutral with regard to jurisdictional claims in published maps and institutional affiliations.

Copyright: (c) 2021 by the authors. Licensee MDPI, Basel, Switzerland. This article is an open access article distributed under the terms and conditions of the Creative Commons Attribution (CC BY) license (https:// creativecommons.org/licenses/by/ $4.0 /)$.
1 Department of Diagnostic and Interventional Radiology, University Medical Center of the Johannes Gutenberg University Mainz, 55131 Mainz, Germany; lukas.mueller@unimedizin-mainz.de (L.M.); felix.hahn@unimedizin-mainz.de (F.H.); aline.maehringer-kunz@unimedizin-mainz.de (A.M.-K.); fabian.stoehr@unimedizin-mainz.de (F.S.); michael.pitton@unimedizin-mainz.de (M.B.P.); christoph.dueber@unimedizin-mainz.de (C.D.)

2 Department of Internal Medicine, University Medical Center of the Johannes Gutenberg University Mainz, 55131 Mainz, Germany; simonjohannes.gairing@unimedizin-mainz.de (S.J.G.); maurice.michel@unimedizin-mainz.de (M.M.); friedrich.foerster@unimedizin-mainz.de (F.F.); arndt.weinmann@unimedizin-mainz.de (A.W.); peter.galle@unimedizin-mainz.de (P.R.G.)

3 Department of General, Visceral and Transplant Surgery, University Medical Center of the Johannes Gutenberg University Mainz, 55131 Mainz, Germany; jens.mittler@unimedizin-mainz.de

4 Department of Radiology, University Hospital of Cologne, 50937 Cologne, Germany; daniel.pinto-dos-santos@uk-koeln.de

* Correspondence: roman.kloeckner@unimedizin-mainz.de; Tel.: +49-6131-17-2019

Simple Summary: The novel CRP-albumin-lymphocyte (CALLY) index has been identified as a highly predictive tool for stratification of patients with hepatocellular carcinoma (HCC) who have undergone tumor resection. This study aimed to validate the predictive ability of the CALLY index in patients with HCC treated with transarterial chemoembolization (TACE). The CALLY index was an independent prognostic predictor for overall survival. However, the CALLY index was not superior to other immunonutritive and inflammation scoring systems in predicting the median OS, although all of the individual parameters of the CALLY index were predictive for the median OS. Thus, future studies should re-evaluate the mathematical calculation of the index for patients with HCC undergoing TACE.

Abstract: The novel CRP-albumin-lymphocyte (CALLY) index is an improved immunonutritive scoring system, based on serum C-reactive protein (CRP), serum albumin, and the lymphocyte count. It has shown promise as a prognostic index for patients with hepatocellular carcinoma (HCC) undergoing resections. This study evaluated the prognostic ability of the CALLY index for patients with HCC undergoing transarterial chemoembolization (TACE). We retrospectively identified 280 treatment-naïve patients with HCC that underwent an initial TACE at our institution, between 2010 and 2020. We compared the CALLY index to established risk factors in univariate and multivariate regression analyses for associations with median overall survival (OS). A low CALLY score was associated with low median OS (low vs. high CALLY: 9.0 vs. 24.0 months, $p<0.001$ ). In the multivariate analysis, the CALLY index remained an independent prognostic predictor $(p=0.008)$. Furthermore, all factors of the CALLY index reached significance in univariate and in-depth multivariate analyses. However, the concordance index (C-index) of the CALLY index (0.60) was similar to the C-indices of established immunonutritive and inflammation scoring systems (range: 0.54 to 0.63 ). In conclusion, the CALLY index showed promise as a stratification tool for patients with HCC undergoing TACE. Notably, the CALLY index was not superior to other immunonutritive and inflammation scoring systems in predicting the median OS. Thus, future studies should re-evaluate the mathematical calculation of the index, particularly the contributions of individual parameters. 
Keywords: hepatocellular carcinoma; transarterial chemoembolization; risk prediction; inflammation index; immunoscoring; CRP-albumin-lymphocyte ratio

\section{Introduction}

Hepatocellular carcinoma (HCC) is the most common primary liver cancer, and it ranks among the deadliest cancer entities worldwide [1,2]. The Barcelona Clinic Liver Cancer (BCLC) classification system was recommended by the Western guidelines of the European Association for the Study of the Liver (EASL) and the American Association for the Study of Liver Diseases as a stratification system for treatment allocations and survival outcome estimations $[3,4]$. According to the BCLC classification, transarterial chemoembolization (TACE) is the standard of care for patients within intermediate-stage HCC $[5,6]$. In clinical practice, patients in the intermediate stage of HCC comprise a heterogeneous group, with broad variations in remnant liver function and tumor burden $[7,8]$. Thus, it remains difficult to predict the prognosis and make treatment decisions for these patients. To date, several scoring systems have been proposed to facilitate decision making [9-11]. However, all of these scores have shown a lack of reproducibility in external validation studies, which limits their integration into the routine clinical workflow $[12,13]$.

Conventional risk models mainly consist of tumor burden and remnant liver function. In the future, these models could be refined. Increases in our knowledge about inflammation and immune system reactions have suggested that these parameters might carry additional prognostic information [14].

The PNI was originally developed in 1980 for patients undergoing gastrointestinal surgery [15]. Since then, the PNI has been identified as a highly predictive index for several cancer entities [16]. The PNI is a combination of the blood albumin level, which indicates the remnant liver function, and the blood lymphocyte count, which indicates the immune system status. In a recent study, we showed that the PNI was a favorable immunonutritive scoring system for survival stratification in patients with HCC that were undergoing TACE [17].

A previous study identified C-reactive protein (CRP) as a prognostic factor for patients with HCC [18]. We hypothesized that CRP might serve as an additional component for immunonutritive scoring because it could reflect the inflammatory component of the tumor microenvironment. Thus, we developed the novel CRP-albumin-lymphocyte (CALLY) index, which combines the PNI with the CRP level. We reasoned that this unique combination of markers for liver function, immune system status, and inflammation might have a synergistic effect in predicting survival in patients with HCC. Indeed, the CALLY index showed promising predictive ability in patients with early HCC that were undergoing a resection [19]. Therefore, a priori, we expected that the CALLY index would show high predictive ability for patients with HCC undergoing TACE. To the best of our knowledge, no previous study has evaluated the CALLY index in patients with HCC that underwent TACE. Furthermore, no direct head-to-head comparison between the CALLY index and the established PNI has been performed.

This study aimed to investigate whether the addition of CRP to existing immune-based prognostic indices might improve the stratification of patients with HCC undergoing TACE. Therefore, the novel CALLY index was evaluated extensively and compared head to head to an immunonutritive index (i.e., the PNI) and to other "purely" immune-based indices.

\section{Materials and Methods}

This analysis of clinical data was approved by the Ethics Committee of the Medical Association of Rhineland Palatinate, Mainz, Germany (permit number 2021-15666). The requirement for informed consent was waived, due to the retrospective nature of the study. Patient records and information were anonymized and de-identified prior to analysis. TRIPOD guidelines were followed for drafting this manuscript. 


\subsection{Patients}

A total of 714 patients with confirmed HCC were referred to our tertiary care center for TACE treatment between January 2010 and November 2020. Among these patients, 434 were excluded from the study for the reasons shown in Figure 1. Thus, 280 treatment-naïve patients with complete laboratory and imaging data were included in the final analysis. In addition, a subgroup analysis was conducted with 154 (55.0\%) patients classified as BCLC stage $\mathrm{B}$; in this stage, TACE is the recommended first-line therapy according to current recommendations $[3,20]$.

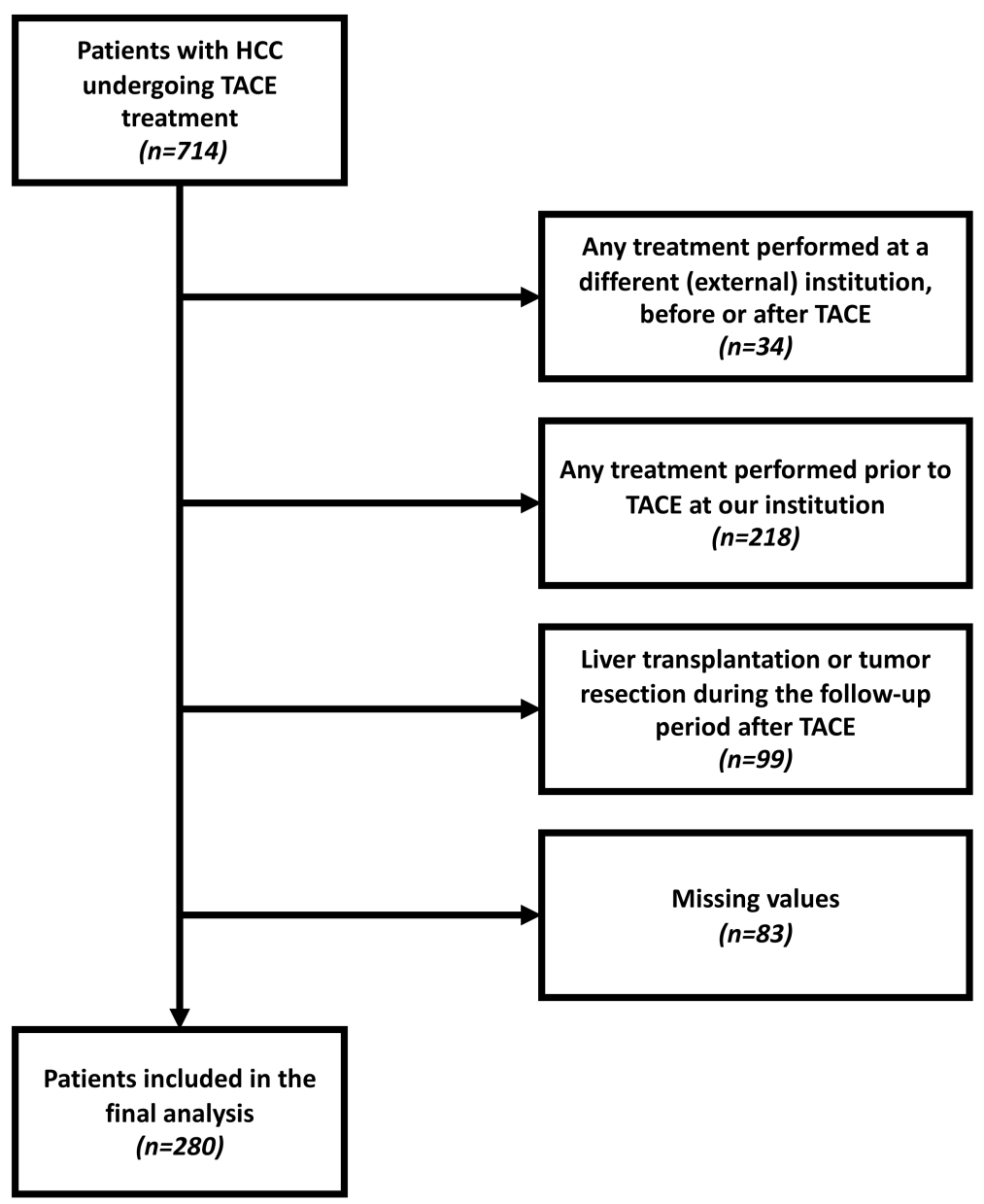

Figure 1. Flowchart showing the various reasons why patients were excluded from this study.

\subsection{Diagnosis, Treatment, and Follow-Up}

As previously reported, histological or image-based EASL criteria were used to diagnose HCC [3,17]. Prior to their first TACE treatment, all patients underwent contrastenhanced computed tomography (CT) or magnetic resonance imaging (MRI) to inform the diagnosis, staging, and treatment planning. These data were extensively discussed in an interdisciplinary tumor board that included hepatologists/oncologists, diagnostic and interventional radiologists, visceral surgeons, pathologists, and radiation therapists.

TACE was performed in a standardized manner, as described in detail previously [21,22]. The follow-up examinations included a clinical examination, blood sample analysis, and cross-sectional imaging. In patients with a viable tumor, imaging was typically repeated every 6 weeks. When the imaging results showed a complete response, the interval was extended to 12 weeks. The primary study endpoint was the median overall survival (OS), defined as the time interval between the initial TACE treatment and death or last follow-up. 


\subsection{Data Acquisition}

The dataset was acquired from the clinical registry unit (CRU), as previously reported [17]. The CRU is an established registry that prospectively collects data on all patients with liver cancer treated at our tertiary referral center [23]. For the present analysis, we retrieved data from the CRU dataset on all baseline characteristics, including demographic data; liver disease status and etiology; laboratory parameters; TACE-related parameters; and information on tumor burden, including the tumor growth pattern, number of lesions, and the diameter of the largest target lesion. When necessary, the CRU dataset was completed with data from the radiology information system, the hospital information system, and the laboratory database.

\subsection{Calculation of the CALLY Index}

The CALLY index was calculated as described previously [19]. Figure 2 presents an overview of the calculation of the CALLY index. We also calculated several other scoring systems, including the neutrophil-to-lymphocyte ratio (NLR), the platelet-to-lymphocyte ratio (PLR), the systemic immune-inflammation index (SII), the integrated liver inflammatory score (ILIS), and the PNI, as previously described [24-28].

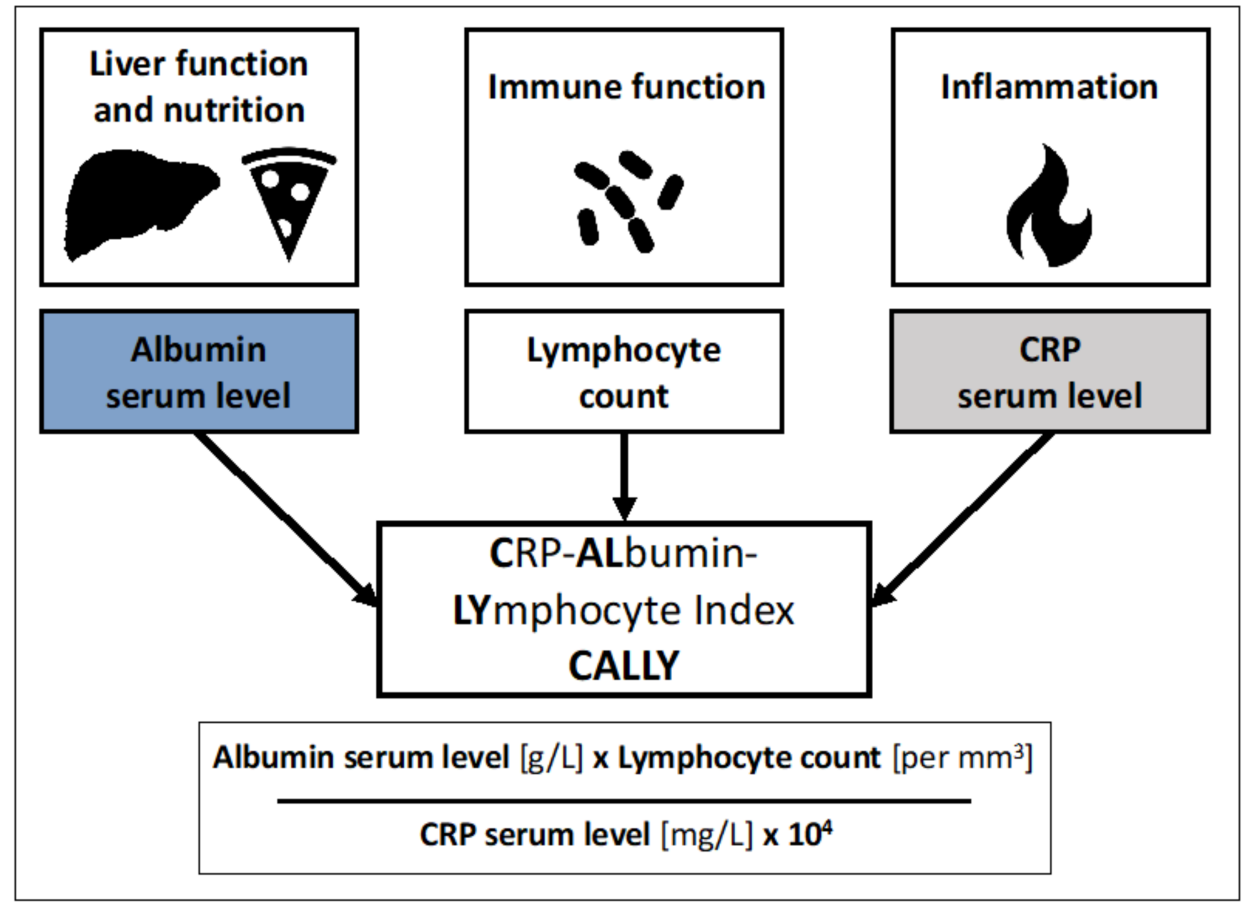

Figure 2. Overview of the formula for calculating the CRP-albumin-lymphocyte (CALLY) index.

\subsection{Statistical Analysis}

Statistical analyses and graphic designs were performed in R 4.0.3 (A Language and Environment for Statistical Computing, R Foundation for Statistical Computing, http:/ /www.R-project.org; last accessed 15 August 2021). Continuous data are reported as the median and range. Categorical and binary baseline parameters are reported as absolute numbers and percentages. Standardized cut-off values for the laboratory parameters were derived from our laboratory database. Optimal stratification was used to calculate the cut-off values for the immunonutritive and inflammation indices, including the CALLY index, with software packages "survminer" and "survival" (https://cran.r-project.org/ package=survminer, https: / /CRAN.R-project.org/packagurvival, last accessed 15 August 2021). Additionally, we used the same software packages to perform survival analyses, including the Kaplan-Meier curves. The different strata of these curves were compared with log-rank testing. The "Number at risk" was defined as the number of patients with 
HCC undergoing TACE that remained alive at the various timepoints. Hazard ratios (HRs) and corresponding 95\% confidence intervals (CIs) were assessed with univariate and multivariate Cox proportional hazard regression models. Further comparisons between the CALLY index and the existing immunonutritive and inflammation indices were performed with Harrell's C concordance index (C-index) with the "Hmisc" package (https: / / cran. r-project.org/package=Hmisc, last accessed 15 August 2021). A C-index of 1.0 indicated perfect predictive power, and a C-index of 0.5 indicated no predictive ability [29]. Values of $p<0.05$ were considered statistically significant for all tests.

\section{Results}

\subsection{Baseline Characteristics}

Patient baseline characteristics are presented in Table 1. A subgroup analysis was performed on $154(55.0 \%)$ patients classified as BCLC stage B (i.e., the subgroup for which TACE was recommended).

Table 1. Baseline characteristics of patients with HCC undergoing TACE included in this study.

\begin{tabular}{|c|c|c|}
\hline Variable & All Patients $(n=280)$ & Patients Classified as BCLC B $(n=154)$ \\
\hline Age, years & $69.5(62.5-75.4)$ & $70.2(63.3-75.6)$ \\
\hline \multicolumn{3}{|l|}{ Sex, $n(\%)$} \\
\hline Female & $46(16.4)$ & $23(14.9)$ \\
\hline Male & $234(83.6)$ & $131(85.1)$ \\
\hline \multicolumn{3}{|l|}{ Etiology, $n(\%)$} \\
\hline Alcohol & $131(46.8)$ & $70(45.5)$ \\
\hline Hepatitis C & $46(16.4)$ & $25(16.2)$ \\
\hline Hepatitis B & $26(9.3)$ & $17(11.0)$ \\
\hline NASH & $27(9.6)$ & $15(9.7)$ \\
\hline Hemochromatosis & $5(1.8)$ & $3(2.0)$ \\
\hline $\mathrm{AIH} / \mathrm{PBC} / \mathrm{PSC}$ & $5(1.8)$ & $3(2.0)$ \\
\hline Unknown/Other & $29(10.4)$ & $13(8.4)$ \\
\hline None & $11(3.9)$ & $8(5.2)$ \\
\hline \multicolumn{3}{|l|}{ Child-Pugh stage, $n(\%)$} \\
\hline $\mathrm{A}$ & $104(37.2)$ & $60(39.0)$ \\
\hline $\mathrm{B}$ & $116(41.4)$ & $74(48.0)$ \\
\hline $\mathrm{C}$ & $25(8.9)$ & 0 \\
\hline No cirrhosis & $35(12.5)$ & $20(13.0)$ \\
\hline \multicolumn{3}{|l|}{ BCLC stage, $n(\%)$} \\
\hline 0 & 0 & 0 \\
\hline A & $45(16.1)$ & 0 \\
\hline $\mathrm{B}$ & $154(55.0)$ & $154(100)$ \\
\hline $\mathrm{C}$ & $58(20.7)$ & 0 \\
\hline $\mathrm{D}$ & $23(8.2)$ & 0 \\
\hline Max. tumor size, $\mathrm{cm}$ & $4.2(2.9-6.4)$ & $4.3(3.2-6.1)$ \\
\hline \multicolumn{3}{|l|}{ Tumor number, $n(\%)$} \\
\hline Unifocal & $55(19.6)$ & 0 \\
\hline Multifocal & $203(72.5)$ & $146(94.8)$ \\
\hline Diffuse growth pattern & $22(7.9)$ & $8(5.2)$ \\
\hline Albumin level, g/L & $31(27-35)$ & $31(28-35)$ \\
\hline Lymphocyte count, per $\mathrm{mm}^{3}$ & $1214(83-1558)$ & $1263(841-1660)$ \\
\hline Bilirubin level, $\mathrm{mg} / \mathrm{dL}$ & $1.3(0.8-2.2)$ & $1.3(0.9-2.0)$ \\
\hline Platelet count, per $\mathrm{nL}$ & $128(87-193)$ & $119(84-194)$ \\
\hline AST level, U/L & $64.5(47.0-95.5)$ & $63.0(47.0-88.5)$ \\
\hline ALT level, U/L & $41.5(28.0-61.0)$ & $42.0(28.0-62.0)$ \\
\hline AP level, U/L & $156.0(114.0-212.3)$ & $146.5(104.0-201.8)$ \\
\hline CRP level, mg/L & $9.0(3.6-18.0)$ & $8.0(3.6-15.8)$ \\
\hline INR & $1.2(1.1-1.3)$ & $1.1(1.0-1.3)$ \\
\hline AFP level, ng/mL & $45.0(8.1-777.0)$ & $48.0(7.6-593.5)$ \\
\hline
\end{tabular}

Values are given as $n$ (\%) or median (interquartile range) unless otherwise noted. NASH, nonalcoholic steatohepatitis. AIH, autoimmune hepatitis. PBC, primary biliary cholangitis. PSC, primary sclerosing cholangitis. BCLC, Barcelona Clinic Liver Cancer. AST, aspartate aminotransferase. ALT, alanine aminotransferase. AFP, alpha fetoprotein. 


\subsection{Survival Analysis}

After applying optimal stratification, the optimal cut-off for the median OS was 1 point for the CALLY index. With this cut-off value, $199(71.1 \%)$ patients had a low CALLY score and $81(28.9 \%)$ had a high CALLY score. The corresponding median OS values for the low and high CALLY groups were 9.0 months and 24.0 months $(p<0.001$, Figure $3 \mathrm{~A}$ ), respectively. For the subgroup of patients classified as BCLC stage $\mathrm{B}$, the optimal stratification yielded the same optimal cut-off of 1 point for the median OS. Thus, $107(69.5 \%)$ patients had a low CALLY score and 47 (30.5\%) patients had a high CALLY score. The corresponding median OS values for the low and high CALLY groups were 13.1 months and 26.2 months ( $p<0.001$, Figure 3B), respectively.

A
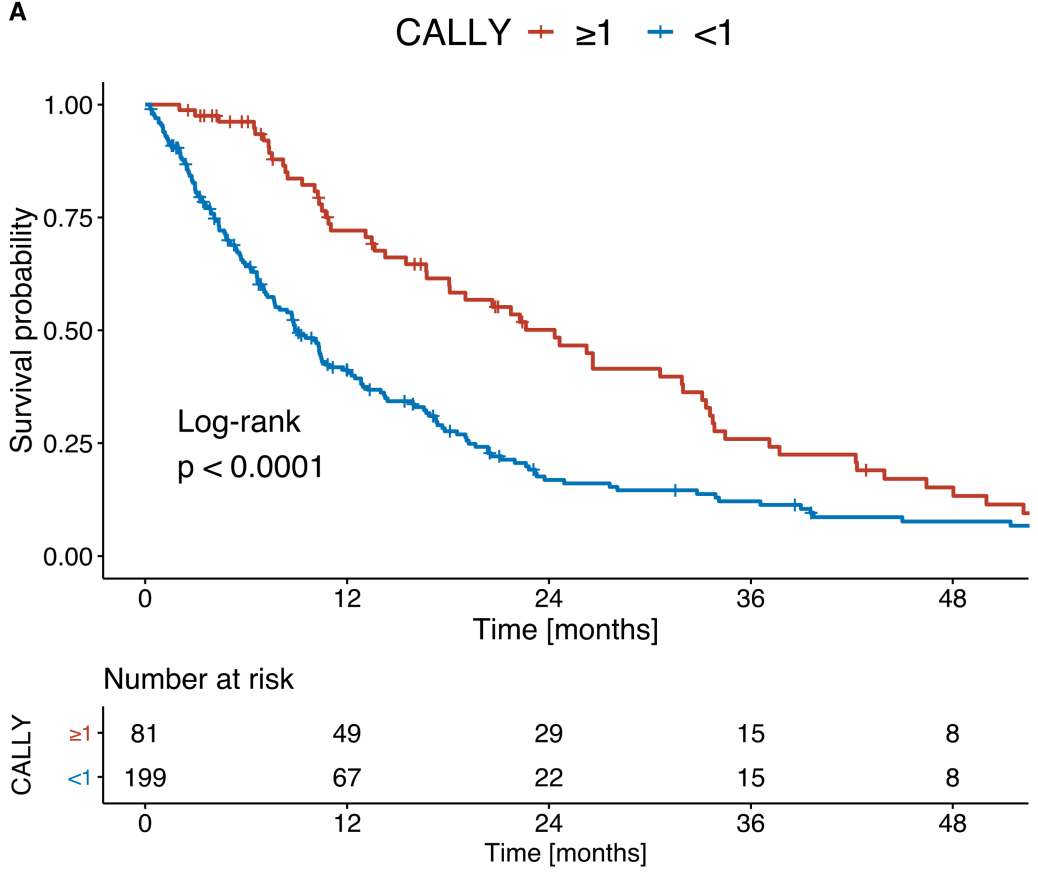

B

$$
\text { CALLY }+\geq 1+<1
$$
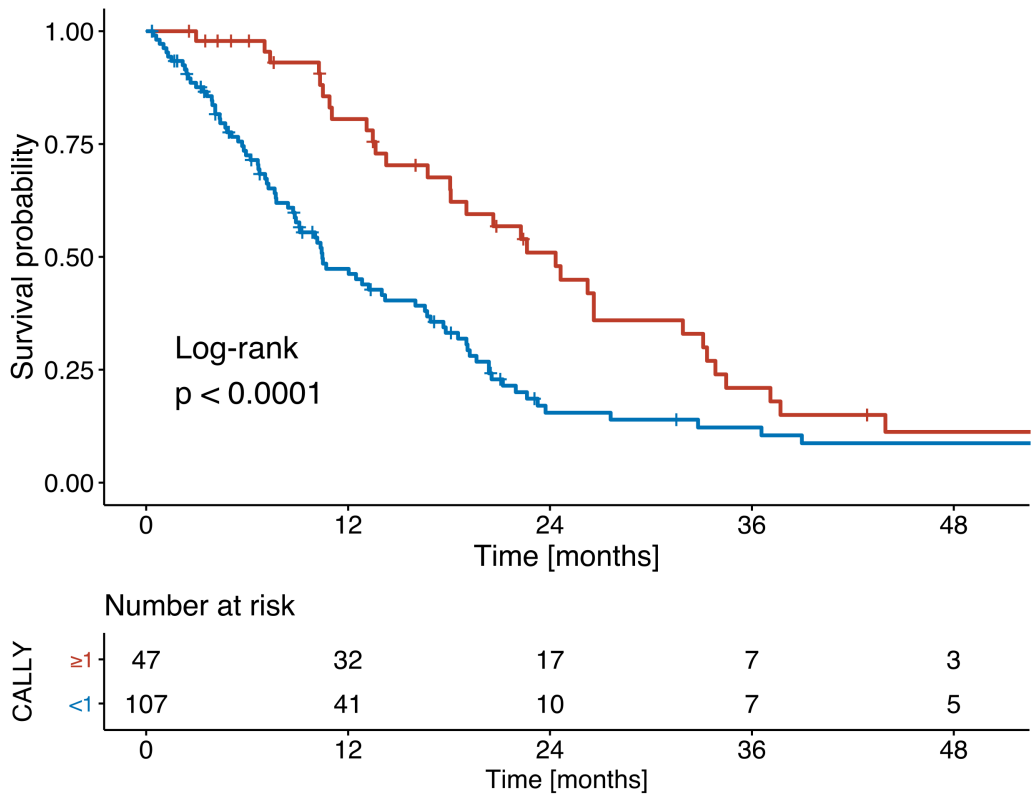

Figure 3. Kaplan-Meier survival curves comparing patients with low and high CALLY scores among (A) all patients and (B) patients classified as BCLC B. 
In the univariate Cox hazard regression analysis, the CALLY index showed high prognostic value. Other factors with high prognostic value were the bilirubin level, the AST level, and the tumor number. In the subsequent multivariate analysis, which included all of the above-mentioned significant factors, only a low CALLY score, a high bilirubin level, and a high AST level remained significant predictors (Table 2).

Table 2. Univariate and multivariate analysis results for all patients.

\begin{tabular}{|c|c|c|c|c|c|c|c|}
\hline \multicolumn{2}{|c|}{ Analysis } & \multicolumn{3}{|c|}{ Univariate } & \multicolumn{3}{|c|}{ Multivariate } \\
\hline Covariate & Cut-Off & HR & $95 \% \mathrm{CI}$ & $p$-Value & HR & $95 \% \mathrm{CI}$ & $p$-Value \\
\hline CALLY & $<1$ point & 1.9 & $1.4-2.6$ & $<0.001$ & 1.5 & $1.1-2.1$ & 0.008 \\
\hline Age & $\geq 70$ years & 1.0 & $0.8-1.3$ & 0.960 & & & \\
\hline AFP & $>400 \mathrm{ng} / \mathrm{mL}$ & 0.9 & $0.7-1.2$ & 0.620 & & & \\
\hline Bilirubin level & $\geq 1.2 \mathrm{mg} / \mathrm{dL}$ & 2.1 & $1.6-2.7$ & $<0.001$ & 1.8 & $1.4-2.5$ & $<0.001$ \\
\hline AST level & $>31 \mathrm{U} / \mathrm{L}$ & 2.0 & $1.1-3.7$ & 0.025 & 2.0 & $1.1-3.6$ & 0.033 \\
\hline ALT level & $\geq 35 \mathrm{U} / \mathrm{L}$ & 1.2 & $0.9-1.6$ & 0.200 & & & \\
\hline INR level & $>1.2$ & 1.1 & $0.8-1.5$ & 0.460 & & & \\
\hline Platelet count & $>150 / \mathrm{nL}$ & 1.3 & $0.9-1.7$ & 0.140 & & & \\
\hline Tumor number & $\geq 2$ & 1.5 & $1.0-2.1$ & 0.027 & 1.2 & $0.8-1.6$ & 0.388 \\
\hline Max. lesion size & $>5.0 \mathrm{~cm}$ & 1.3 & $1.0-1.7$ & 0.058 & & & \\
\hline
\end{tabular}

AFP, alpha fetoprotein. AST, aspartate aminotransferase. ALT, alanine aminotransferase.

In the subgroup of patients classified as BCLC stage B, the CALLY score, the bilirubin level, and the tumor lesion size showed high predictive value in the univariate Cox hazard regression. In the multivariate Cox hazard regression, only a low CALLY score and a high bilirubin level remained significant risk factors (Table 3).

Table 3. Univariate and multivariate analysis results for patients classified as BCLC B.

\begin{tabular}{|c|c|c|c|c|c|c|c|}
\hline \multicolumn{2}{|c|}{ Analysis } & \multicolumn{3}{|c|}{ Univariate } & \multicolumn{3}{|c|}{ Multivariate } \\
\hline Covariate & Cut-off & HR & $95 \% \mathrm{CI}$ & $p$-Value & HR & $95 \% \mathrm{CI}$ & $p$-Value \\
\hline CALLY & $<1$ point & 1.9 & $1.3-2.9$ & 0.002 & 1.5 & $1.1-2.1$ & 0.010 \\
\hline Age & $\geq 70$ years & 1.0 & $0.7-1.5$ & 0.930 & & & \\
\hline AFP & $>400 \mathrm{ng} / \mathrm{mL}$ & 1.0 & $0.7-1.4$ & 0.790 & & & \\
\hline Bilirubin level & $\geq 1.2 \mathrm{mg} / \mathrm{dL}$ & 1.9 & $1.3-2.8$ & $<0.001$ & 1.9 & $1.4-2.5$ & $<0.001$ \\
\hline AST level & $>31 \mathrm{U} / \mathrm{L}$ & 1.5 & $0.7-2.9$ & 0.280 & & & \\
\hline ALT level & $\geq 35 \mathrm{U} / \mathrm{L}$ & 1.3 & $0.9-1.9$ & 0.230 & & & \\
\hline INR level & $>1.2$ & 1.1 & $0.7-1.6$ & 0.770 & & & \\
\hline Platelet count & $>150 / \mathrm{nL}$ & 1.1 & $0.7-1.7$ & 0.720 & & & \\
\hline Max. lesion size & $>5.0 \mathrm{~cm}$ & 1.5 & $1.0-2.3$ & 0.035 & 1.3 & $1.0-1.7$ & 0.069 \\
\hline
\end{tabular}

AFP, alpha fetoprotein. AST, aspartate aminotransferase. ALT, alanine aminotransferase.

In a separate, in-depth analysis of the individual CALLY parameters, all factors were highly predictive of the median OS in univariate and multivariate analyses, when optimal stratification was applied. Similarly, in the analysis of the subgroup classified as BLCL B, all the individual CALLY factors reached significance in both univariate and multivariate analyses (Table 4).

When we compared the CALLY index to other established immunonutritive and inflammation scoring systems (i.e., the NLR, PLR, PNI, SII, and ILIS), we found that the C-index of the CALLY index was slightly lower than the C-index of the PNI and slightly higher than the C-indices of the other scores (Table 5). This tendency was similar when we performed this comparison in the subgroup of patients classified as BLCL B (Table 5). 
Table 4. Univariate and multivariate Cox proportional hazard regression model results for evaluating the individual CALLY parameters.

\begin{tabular}{|c|c|c|c|c|c|c|}
\hline \multirow{2}{*}{$\begin{array}{l}\text { Analysis } \\
\text { Covariate }\end{array}$} & \multicolumn{3}{|c|}{ Univariate } & \multicolumn{3}{|c|}{ Multivariate } \\
\hline & HR & $95 \%$ CI & $p$-Value & HR & $95 \% \mathrm{CI}$ & $p$-Value \\
\hline \multicolumn{7}{|l|}{ All patients $(n=280)$} \\
\hline Serum albumin level $\leq 31 \mathrm{~g} / \mathrm{L}$ & 2.5 & $1.9-3.3$ & $<0.001$ & 1.9 & $1.4-2.6$ & $<0.001$ \\
\hline Total lymphocyte count $\leq 647.9 / \mathrm{mm}^{3}$ & 1.7 & $1.2-2.5$ & 0.005 & 1.5 & $1.0-2.2$ & 0.036 \\
\hline Serum CRP level $\leq 12 \mathrm{mg} / \mathrm{L}$ & 3.7 & $2.8-5.0$ & $<0.001$ & 3.0 & $2.2-4.1$ & $<0.001$ \\
\hline \multicolumn{7}{|l|}{ BCLC B subgroup $(\mathrm{n}=164)$} \\
\hline Serum albumin level $\leq 29 \mathrm{~g} / \mathrm{L}$ & 2.6 & $1.7-3.8$ & $<0.001$ & 2.4 & $1.6-3.6$ & $<0.001$ \\
\hline Total lymphocyte count $\leq 727 / \mathrm{mm}^{3}$ & 2.2 & $1.4-3.5$ & $<0.001$ & 1.7 & $1.0-2.7$ & 0.038 \\
\hline Serum CRP level $\leq \overline{4} \mathrm{mg} / \mathrm{L}$ & 2.0 & $1.3-3.1$ & $<0.001$ & 2.0 & $1.3-3.0$ & 0.001 \\
\hline
\end{tabular}

CRP, C-reactive protein. HR, hazard ratio. CI, confidence interval.

Table 5. Comparison of the CALLY index to existing immunonutritive and inflammation indices.

\begin{tabular}{|c|c|c|c|c|c|c|}
\hline \multicolumn{2}{|c|}{ Score } & Median OS & HR & $95 \%$ CI & $p$-Value & C-Index \\
\hline \multicolumn{7}{|c|}{ All Patients $(n=280)$} \\
\hline \multirow{2}{*}{ CALLY } & $\geq 1$ & 24.0 & & Reference & & 0.60 \\
\hline & $<1$ & 9.0 & 1.9 & $1.4-2.6$ & $<0.001$ & \\
\hline \multirow{2}{*}{ NLR } & $\leq 3$ & 16.5 & & Reference & & 0.59 \\
\hline & $>3$ & 7.6 & 1.8 & $1.4-2.4$ & $<0.001$ & \\
\hline \multirow{2}{*}{ PLR } & $<164$ & 12.8 & & Reference & & 0.54 \\
\hline & $\geq 164$ & 10.2 & 1.3 & $1.0-1.8$ & 0.082 & \\
\hline \multirow{2}{*}{ PNI } & $>36$ & 18.8 & & Reference & & 0.63 \\
\hline & $\leq 36$ & 6.5 & 2.4 & $1.8-3.2$ & $<0.001$ & \\
\hline \multirow{2}{*}{ SII } & $<664$ & 13.8 & & Reference & & 0.56 \\
\hline & $\geq 664$ & 8.6 & 1.5 & $1.1-2.1$ & 0.006 & \\
\hline \multirow[b]{2}{*}{ ILIS } & $<11$ & 18.8 & & Reference & & 0.57 \\
\hline & $\geq 11$ & 10.2 & 1.5 & $1.3-2.5$ & $<0.001$ & \\
\hline \multicolumn{7}{|c|}{ BLCL B subgroup $(n=164)$} \\
\hline \multirow[t]{2}{*}{ CALLY } & $\geq 1$ & 26.2 & & Reference & & 0.61 \\
\hline & $<1$ & 13.1 & 1.9 & $1.3-2.9$ & 0.002 & \\
\hline \multirow[t]{2}{*}{ NLR } & $\leq 3$ & 18.3 & & Reference & & 0.59 \\
\hline & $>3$ & 9.0 & 2.5 & $1.6-3.8$ & $<0.001$ & \\
\hline \multirow[t]{2}{*}{ PLR } & $<214$ & 16.5 & & Reference & & 0.55 \\
\hline & $\geq 214$ & 7.5 & 2.5 & $1.4-4.4$ & 0.002 & \\
\hline \multirow[t]{2}{*}{ PNI } & $>39$ & 20.9 & & Reference & & 0.63 \\
\hline & $\leq 39$ & 10.3 & 1.9 & $1.3-2.8$ & $<0.001$ & \\
\hline \multirow[t]{2}{*}{ SII } & $<622$ & 16.7 & & Reference & & 0.55 \\
\hline & $\geq 622$ & 10.0 & 1.9 & $1.2-3.1$ & 0.007 & \\
\hline \multirow[t]{2}{*}{ ILIS } & $<31$ & 17.9 & & Reference & & 0.58 \\
\hline & $\geq 31$ & 10.4 & 2.0 & $1.4-3.0$ & $<0.001$ & \\
\hline
\end{tabular}

NLR, neutrophil-to-lymphocyte ratio. PLR, platelet-to-lymphocyte ratio. SII, systemic immune-inflammation index. ILIS, integrated liver inflammatory score. PNI, prognostic nutritional index.

\section{Discussion}

To the best of our knowledge, this study is the first to investigate the role of the CALLY index for patients with HCC that underwent TACE. The CALLY index could stratify patients according to the median OS, and it remained an independent prognostic factor in multivariate analyses for all patients, including the subgroup of patients classified as BLCL B. In addition, each individual parameter of the CALLY index, namely, the serum CRP level, the serum albumin level, and the lymphocyte count, was highly predictive of the median OS. Nevertheless, the C-index of the CALLY index was not superior to the $\mathrm{C}$-indices of the other investigated immunonutritive and inflammation scoring systems.

In more than $80 \%$ of cases, HCC develops from liver cirrhosis [3]. In the injured milieu, inflammatory processes and counter-regulation have been identified as the key drivers of HCC development and progression [30,31]. Lymphocytes act as counter-regulators to non-resolving inflammation and transformation due to unregulated proliferation. Indeed, 
lymphocytes are an important part of the host tumor defense mechanism because they inhibit cell proliferation and migration [30,32].

Immune-based scoring has been widely investigated for patients with HCC $[25,26]$. Indeed, several recent studies have investigated the prognostic roles of various indices $[33,34]$. In particular, the NLR and PLR have been investigated extensively as prognostic indices for patients with HCC undergoing TACE [33,35]. However, the prognostic ability of both those indices varied in several validation studies. The SII is based on the factors included in the NLR and PLR indices, and it was recently validated as a potential novel scoring system for patients with HCC undergoing TACE [34]. Nevertheless, the predictive ability of the SII was not superior to that of the NLR and PLR, consistent with our findings in the present study. Additionally, the ILIS was recently promoted as an immune-based score specifically for patients with HCC. The first validation study, conducted in patients undergoing TACE, demonstrated a C-index of 0.625 , which was higher than the C-index found in our dataset. Nevertheless, future large-scale studies on both the SII and the ILIS are mandatory to evaluate their prognostic predictive abilities, compared to existing immune-based indices. In contrast to immune-based indices, immunonutritive indices integrate the nutritional status into the prognostic score. Theoretically, the immunonutritional status should lead to a more integrated patient evaluation. Accordingly, in a recent study, we demonstrated that the PNI showed promise as a prognostic indicator for patients with HCC undergoing TACE [17]. However, studies on the immunonutritional status are scarce for this patient group, and future large-scale studies are needed. Table 6 summarizes the characteristics, concepts, and the pros and cons of the various immunonutritive and immune-based indices, with notes on current and future research strategies.

Table 6. Overview of various aspects of the included immunonutritive and immune-based indices.

\begin{tabular}{|c|c|c|c|c|c|c|}
\hline Index & $\begin{array}{l}\text { Concept and } \\
\text { Characteristics }\end{array}$ & $\begin{array}{l}\text { Included } \\
\text { Parameters }\end{array}$ & Pros & Cons & $\begin{array}{c}\text { Current Research } \\
\text { Status }\end{array}$ & $\begin{array}{l}\text { Future Research } \\
\text { Strategies }\end{array}$ \\
\hline \multicolumn{7}{|c|}{ Immunonutritive Indices } \\
\hline CALLY & $\begin{array}{c}\text { - combines } \\
\text { inflammation, } \\
\text { immune response, } \\
\text { and nutritional status } \\
\text { markers (aspects of } \\
\text { the PNI) } \\
\text { - for liver disease, } \\
\text { albumin functions as } \\
\text { an indicator of } \\
\text { liver function }\end{array}$ & $\begin{array}{c}\text { - CRP } \\
\text { - albumin } \\
\text { - lymphocyte count }\end{array}$ & $\begin{array}{l}\text { - novel combination } \\
\text { of inflammation, } \\
\text { immune response, } \\
\text { nutritional status, } \\
\text { and liver function } \\
\text { markers provides a } \\
\text { more holistic } \\
\text { assessment }\end{array}$ & $\begin{array}{l}\text { - scarce literature } \\
\text { available } \\
\text { - in this study, } \\
\text { CALLY was not } \\
\text { superior to } \\
\text { previously } \\
\text { established scoring } \\
\text { systems }\end{array}$ & $\begin{array}{l}\text { - designed for a } \\
\text { cohort of patients } \\
\text { with HCC } \\
\text { undergoing } \\
\text { resections [19] } \\
\text { - only validated in } \\
\text { this study for } \\
\text { patients with HCC } \\
\text { undergoing TACE }\end{array}$ & $\begin{array}{l}\text { - further validation } \\
\text { needed for patients } \\
\text { with HCC } \\
\text { undergoing TACE } \\
\text { - validation for } \\
\text { assessing other HCC } \\
\text { treatment options } \\
\text { - efficacy of CALLY } \\
\text { combined with } \\
\text { bilirubin } \\
\text { - the mathematical } \\
\text { calculation may } \\
\text { require improvement }\end{array}$ \\
\hline PNI & $\begin{array}{l}\text { - combines immune } \\
\text { response and } \\
\text { nutritional status } \\
\text { markers }\end{array}$ & $\begin{array}{l}\text { - albumin } \\
\text { - lymphocyte count }\end{array}$ & $\begin{array}{l}\text { - combination of } \\
\text { immune response } \\
\text { and nutritional } \\
\text { status markers }\end{array}$ & $\begin{array}{l}\text { - few studies } \\
\text { available on } \\
\text { patients with HCC } \\
\text { undergoing TACE } \\
\text { - divergent results } \\
\text { regarding the } \\
\text { predictive ability of } \\
\text { PNI } \\
\text { - the mathematical } \\
\text { calculation may } \\
\text { require } \\
\text { improvement }\end{array}$ & $\begin{array}{c}\text { - designed for } \\
\text { patients with gastric } \\
\text { cancer [15] } \\
\text { - extensively } \\
\text { validated for various } \\
\text { cancer entities } \\
\text { - few studies } \\
\text { available for patients } \\
\text { with HCC } \\
\text { undergoing TACE } \\
\text { - divergent results on } \\
\text { its predictive ability } \\
\text { - PNI combined with } \\
\text { ALBI was identified } \\
\text { as a novel, feasible } \\
\text { stratification system } \\
\text { for patients with } \\
\text { HCC undergoing } \\
\text { TACE }\end{array}$ & $\begin{array}{c}\text { - further, large-scale } \\
\text { validation needed for } \\
\text { patients with HCC } \\
\text { undergoing TACE } \\
\text { - the integration of } \\
\text { immunonutrition } \\
\text { into existing } \\
\text { stratification systems }\end{array}$ \\
\hline
\end{tabular}


Table 6. Cont.

\begin{tabular}{|c|c|c|c|c|c|c|}
\hline Index & $\begin{array}{l}\text { Concept and } \\
\text { Characteristics }\end{array}$ & $\begin{array}{l}\text { Included } \\
\text { Parameters }\end{array}$ & Pros & Cons & $\begin{array}{c}\text { Current Research } \\
\text { Status }\end{array}$ & $\begin{array}{l}\text { Future Research } \\
\text { Strategies }\end{array}$ \\
\hline \multicolumn{7}{|c|}{ Other Immune-Based Indices } \\
\hline NLR & $\begin{array}{l}\text { - captures shifts in } \\
\text { the relationships } \\
\text { between blood cells, } \\
\text { due to immune } \\
\text { response effects }\end{array}$ & $\begin{array}{l}\text { - neutrophil count } \\
\text { - lymphocyte count }\end{array}$ & $\begin{array}{l}\text { - simple calculation } \\
\text { - well investigated }\end{array}$ & $\begin{array}{c}\text { - nutritional status } \\
\text { not included } \\
\text { - divergent results in } \\
\text { studies that } \\
\text { compared NLR to } \\
\text { other } \\
\text { immune-based } \\
\text { indices }\end{array}$ & $\begin{array}{l}\text { - designed for the } \\
\text { stratification of } \\
\text { critically ill patients, } \\
\text { and validated in } \\
\text { patients with } \\
\text { colorectal cancer, in } \\
\text { an oncologic context } \\
\text { [36] } \\
\text { - extensively } \\
\text { validated for various } \\
\text { cancer entities, } \\
\text { including patients } \\
\text { with HCC } \\
\text { undergoing TACE }\end{array}$ & $\begin{array}{l}\text { - NLR combined } \\
\text { with nutritional } \\
\text { status markers } \\
\text { - NLR combined with } \\
\text { liver function } \\
\text { markers } \\
\text { - large-scale } \\
\text { validation for } \\
\text { patients with HCC } \\
\text { undergoing TACE } \\
\text { - integration into } \\
\text { existing stratification } \\
\text { tools }\end{array}$ \\
\hline PLR & $\begin{array}{l}\text { - captures shifts in } \\
\text { the relationships } \\
\text { between blood cells, } \\
\text { due to immune } \\
\text { response effects }\end{array}$ & $\begin{array}{l}\text { - platelet count } \\
\text { - lymphocyte count }\end{array}$ & $\begin{array}{l}\text { - simple calculation } \\
\text { - well investigated }\end{array}$ & $\begin{array}{c}\text { - nutritional status } \\
\text { not included } \\
\text { - divergent results in } \\
\text { studies that } \\
\text { compared PLR to } \\
\text { other } \\
\text { immune-based } \\
\text { indices }\end{array}$ & $\begin{array}{l}\text { - designed for the } \\
\text { stratification of } \\
\text { patients with } \\
\text { pancreatic cancer [37] } \\
\text { - extensively } \\
\text { validated for patients } \\
\text { with HCC } \\
\text { undergoing TACE }\end{array}$ & $\begin{array}{l}\text { - PLR combined with } \\
\text { nutritional status } \\
\text { markers } \\
\text { - PLR combined with } \\
\text { liver function } \\
\text { markers } \\
\text { - further large-scale } \\
\text { validation for } \\
\text { patients with HCC } \\
\text { undergoing TACE } \\
\text { - integration into } \\
\text { existing stratification } \\
\text { tools }\end{array}$ \\
\hline SII & $\begin{array}{l}\text { - combines } \\
\text { inflammation and } \\
\text { immune response } \\
\text { markers }\end{array}$ & $\begin{array}{l}\text { - lymphocyte count } \\
\text { - neutrophil count } \\
\text { - platelet count }\end{array}$ & $\begin{array}{c}\text { - extensively } \\
\text { validated for } \\
\text { patients with HCC }\end{array}$ & $\begin{array}{l}\text { - nutritional status } \\
\text { not included } \\
\text { - literature is scarce } \\
\text { for patients } \\
\text { undergoing TACE }\end{array}$ & $\begin{array}{l}\text { - designed for the } \\
\text { stratification of } \\
\text { patients with HCC } \\
\text { undergoing } \\
\text { resections [38] } \\
\text { - extensively } \\
\text { validated for various } \\
\text { cancer entities } \\
\text { - few studies on the } \\
\text { role of the SII in } \\
\text { patients undergoing } \\
\text { TACE }\end{array}$ & $\begin{array}{c}\text { - SII combined with } \\
\text { nutritional status } \\
\text { markers } \\
\text { - SII combined with } \\
\text { liver function } \\
\text { markers } \\
\text { - further large-scale } \\
\text { validation for } \\
\text { patients with HCC } \\
\text { undergoing TACE } \\
\text { - integration into } \\
\text { existing stratification } \\
\text { tools }\end{array}$ \\
\hline ILIS & $\begin{array}{c}\text { - combines } \\
\text { inflammation, liver } \\
\text { function, and tumor } \\
\text { markers } \\
\text { - specifically } \\
\text { developed for } \\
\text { patients with HCC }\end{array}$ & $\begin{array}{c}\text { - albumin } \\
\text { - bilirubin } \\
\text { - alkaline } \\
\text { phosphatase } \\
\text { - neutrophil count }\end{array}$ & $\begin{array}{l}\text { - index is specific } \\
\text { for HCC } \\
\text { - includes tumor } \\
\text { and liver function } \\
\text { markers }\end{array}$ & $\begin{array}{c}\text { - complex } \\
\text { calculation } \\
\text { - scarce literature for } \\
\text { patients with HCC, } \\
\text { particularly for } \\
\text { patients undergoing } \\
\text { TACE }\end{array}$ & $\begin{array}{l}\text { - specifically } \\
\text { designed for patients } \\
\text { with HCC [27] } \\
\text { - only one external } \\
\text { validation study } \\
\text { available }\end{array}$ & $\begin{array}{c}\text { - large-scale } \\
\text { validation is } \\
\text { mandatory } \\
\text { - integration into } \\
\text { existing stratification } \\
\text { tools }\end{array}$ \\
\hline
\end{tabular}

Several conventional tools and scoring systems have been developed to provide support for clinicians making treatment decisions for patients with HCC that undergo TACE [39]. Unfortunately, despite promising initial results, all the conventional risk scores have failed in external evaluations [9-13]. All these scores mainly include tumor size, tumor number, and alpha fetoprotein as surrogates for the tumor burden and remnant liver function. Historically, liver function in patients with HCC is assessed with the Child-Pugh score. This score combines albumin, the international normalized ratio (INR), bilirubin, ascites, and hepatic encephalopathy [40]. However, estimations of ascites and hepatic encephalopathy rely on subjective interpretations; therefore, more quantitative assessment systems have been validated for patients with HCC undergoing TACE [41-43]. These quantitative systems are based on laboratory parameters such as the albumin-bilirubin (ALBI) grade, the Model of End Stage Liver Disease (MELD) score, and the MELD-Natrium score. Nevertheless, liver function assessments have shown variable prognostic abilities. Furthermore, liver function assessment is only one of several assessments considered in making treatment decisions for patients with HCC that undergo TACE. Thus, additional aspects of patients' condition must be considered for a more holistic patient evaluation.

Overall, none of the established risk scores or liver function estimates include recent insights on how inflammation, the immune response, and nutrition affect HCC development and progression. Thus, immunonutritive indices have the potential to reflect more 
aspects of cancer development and progression. Accordingly, these indices could improve patient stratification and enable more individualized prognosis predictions. Inflammation and immunonutritive indices will not replace liver function and tumor burden assessments in treatment decision making; however, they could provide a more holistic picture of the patient's overall status.

In this study, we first investigated the role of the novel CALLY index in predicting prognosis in patients with HCC undergoing TACE. Compared to the above-mentioned existing indices, the CALLY index combines markers of inflammation, the immune response, and nutritional status. Based on the recent insights into the prognostic roles of immunonutrition and CRP for patients with HCC undergoing TACE, the combination of these markers and their evaluation seemed to be the next step for advancing the field $[18,44]$. Our univariate and multivariate analyses confirmed that including all these factors in the CALLY index showed promising results. Interestingly, the CALLY index showed only slightly superior predictive ability compared to the established immunonutritive and immune-based scoring systems. Moreover, the CALLY index was slightly inferior to the PNI in predicting the median OS of patients with HCC undergoing TACE. Consequently, we conclude that the combination of inflammation, immune response, and nutritional status markers has the potential of improving immunonutritive scoring; thus, the CALLY index should be integrated into the above-mentioned existing stratification systems, as an additional component of holistic patient evaluations. However, the CALLY index calculation might not be optimal for patients with HCC undergoing TACE. Future studies should re-evaluate the mathematical calculation of the CALLY index to optimize the contributions of the individual parameters. Additionally, large-scale prospective trials could facilitate the identification of optimal cut-off values for further refining the CALLY index.

To date, because the CALLY index is a novel prediction system, we lack reference values. Thus, the CALLY index equation might be only partly suitable for patients with HCC undergoing TACE. Future studies should re-evaluate the mathematical calculation of the CALLY index, particularly the contributions of the individual parameters. Additionally, large-scale prospective trials could facilitate the identification of optimal cut-off values that can be used to refine the CALLY index further.

Our multivariate analysis confirmed that bilirubin was a highly predictive factor for the entire patient cohort, and for the subgroup of patients classified as BLCL B. Thus, the predictive ability of the CALLY index might be further improved if it were combined with the bilirubin level. Indeed, the albumin-bilirubin (ALBI) grade is a well-established scoring system for evaluating remnant liver function [41,42]. A previous study showed that the combination of the PNI, an immunonutritive scoring system, and the ALBI grade was a promising stratification tool for evaluating patients with HCC for remnant liver function and immunonutritive status [45]. In a recent study, we showed that the so-called ALBI-PNI was feasible, particularly among patients undergoing TACE [46]. Thus, our future research effort could include the integration of CRP as a relevant prognostic factor in the ALBI-PNI system.

In the future, immunonutritive scoring could be combined with imaging assessments of body composition parameters. In particular, the estimation of sarcopenia, defined as the quantitative and qualitative loss of skeletal muscle mass, has been identified as a highly predictive factor for patients with HCC $[47,48]$. In combination with the promising results on immunonutritive scoring, imaging might further enhance appraisals of patient status and improve stratification and scoring systems.

This study had several limitations. First, it was a single-center study. Second, the sample size was only moderate $(n=280)$. However, we only included patients with complete datasets because we actively decided against imputing missing values. Furthermore, we only included patients treated from 2010 and later to ensure comparability in the diagnosis, treatment, and follow-up procedures. In addition, to avoid bias, we excluded patients that underwent subsequent liver transplantation or other curative treatments after 
TACE [43]. Nevertheless, compared to previous studies on this issue, our sample size was comparable [19].

\section{Conclusions}

We found that the novel CALLY index was a promising stratification tool for patients with HCC undergoing TACE. Notably, although all three individual parameters were predictive of the median OS, the predictive ability of the CALLY index was not superior to the abilities of other immunonutritive and inflammation scoring systems. Thus, future large-scale studies should re-evaluate the mathematical calculation of the CALLY index, particularly the contributions of the individual parameters.

Author Contributions: L.M., F.H., A.M.-K., F.S., S.J.G., M.M., F.F., A.W., P.R.G., J.M., D.P.d.S., M.B.P., C.D. and R.K. devised the study, assisted in data collection, participated in the interpretation of the data, and helped draft the manuscript. L.M., F.S., S.J.G., A.W. and F.H. carried out the data collection. A.M.-K., M.M., P.R.G., J.M., D.P.d.S., M.B.P., C.D. and R.K. supported the data collection efforts. L.M., F.H., D.P.d.S. and R.K. created all of the figures and participated in the interpretation of data. L.M., F.H., D.P.d.S. and R.K. performed the statistical analysis. All authors have read and agreed to the published version of the manuscript.

Funding: This research received no external funding.

Institutional Review Board Statement: This study was conducted according to the guidelines of the Declaration of Helsinki and approved by the responsible Ethics Committee of the Medical Association of Rhineland Palatinate, Mainz, Germany (permit number 2021-15666), for the retrospective analysis of clinical data. Additional examinations were not performed.

Informed Consent Statement: According to the responsible Ethics Committee of the Medical Association of Rhineland Palatinate, Mainz, Germany, informed consent was not needed given the retrospective study design. Patient records and clinical information were de-identified prior to analysis.

Data Availability Statement: Data cannot be shared publicly because of institutional and national data policy restrictions imposed by the Ethics Committee of the Medical Association of Rhineland Palatinate, Mainz, Germany, since the data contain potentially identifying patient information. Data are available upon request for researchers who meet the criteria for access to confidential data.

Acknowledgments: L.M., F.S., S.J.G. and M.M. are supported by the Clinician Scientist Fellowship “Else Kröner Research College: 2018_Kolleg.05".

Conflicts of Interest: A.W. has received speaker fees and travel grants from Bayer. R.K. has received consultancy fees from Boston Scientific, Bristol-Myers Squibb, Guerbet, Roche, and SIRTEX and lectures fees from BTG, EISAI, Guerbet, Ipsen, Roche, Siemens, SIRTEX, and MSD Sharp \& Dohme. F.F. reports receiving consulting and lecture fees from Roche, and lecture fees from Lilly and Pfizer. P.R.G. reports receiving consulting and lecture fees from Adaptimmune, AstraZeneca, Bayer, BMS, Eisai, Ipsen, Lilly, MSD, Roche, and Sirtex. The funders had no role in the design of the study; in the collection, analyses, or interpretation of data; in the writing of the manuscript, or in the decision to publish the results.

\section{References}

1. Global Burden of Disease Liver Cancer Collaboration. The Burden of Primary Liver Cancer and Underlying Etiologies from 1990 to 2015 at the Global, Regional, and National Level: Results From the Global Burden of Disease Study 2015. JAMA Oncol. 2017, 3, 1683-1691. [CrossRef] [PubMed]

2. Llovet, J.M.; Zucman-Rossi, J.; Pikarsky, E.; Sangro, B.; Schwartz, M.; Sherman, M.; Gores, G. Hepatocellular carcinoma. Nat. Rev. Dis. Prim. 2016, 2, 16018. [CrossRef] [PubMed]

3. Galle, P.R.; Forner, A.; Llovet, J.M.; Mazzaferro, V.; Piscaglia, F.; Raoul, J.-L.; Schirmacher, P.; Vilgrain, V. EASL Clinical Practice Guidelines: Management of hepatocellular carcinoma. J. Hepatol. 2018, 69, 182-236. [CrossRef] [PubMed]

4. Heimbach, J.K.; Kulik, L.M.; Finn, R.S.; Sirlin, C.B.; Abecassis, M.M.; Roberts, L.R.; Zhu, A.X.; Murad, M.H.; Marrero, J.A. AASLD guidelines for the treatment of hepatocellular carcinoma. Hepatology 2018, 67, 358-380. [CrossRef] [PubMed]

5. Llovet, J.M.; Brú, C.; Bruix, J. Prognosis of hepatocellular carcinoma: The BCLC staging classification. In Seminars in Liver Disease; Thieme Medical Publishers, Inc.: New York, NY, USA, 1999; Volume 19, pp. 329-338.

6. Forner, A.; Reig, M.; Bruix, J. Hepatocellular carcinoma. Lancet 2018, 391, 1301-1314. [CrossRef] 
7. Bolondi, L.; Burroughs, A.; Dufour, J.-F.; Galle, P.R.; Mazzaferro, V.; Piscaglia, F.; Raoul, J.L.; Sangro, B. Heterogeneity of patients with intermediate (BCLC B) Hepatocellular Carcinoma: Proposal for a subclassification to facilitate treatment decisions. In Seminars in Liver Disease; Thieme Medical Publishers: New York, NY, USA, 2012; Volume 32, pp. 348-359.

8. Chow, P.K.H.; Choo, S.P.; Ng, D.C.E.; Lo, R.H.G.; Wang, M.L.C.; Toh, H.C.; Tai, D.W.M.; Goh, B.K.P.; San Wong, J.; Tay, K.H.; et al. Heterogeneity and subclassification of barcelona clinic liver cancer stage B. Liver Cancer 2016, 5, 91-96.

9. Hucke, F.; Pinter, M.; Graziadei, I.; Bota, S.; Vogel, W.; Müller, C.; Heinzl, H.; Waneck, F.; Trauner, M.; Peck-Radosavljevic, M.; et al. How to STATE suitability and START transarterial chemoembolization in patients with intermediate stage hepatocellular carcinoma. J. Hepatol. 2014, 61, 1287-1296. [CrossRef] [PubMed]

10. Kadalayil, L.; Benini, R.; Pallan, L.; O’Beirne, J.; Marelli, L.; Yu, D.; Hackshaw, A.; Fox, R.; Johnson, P.; Burroughs, A.K.; et al. A simple prognostic scoring system for patients receiving transarterial embolisation for hepatocellular cancer. Ann. Oncol. 2013, 24, 2565-2570. [CrossRef] [PubMed]

11. Park, Y.; Kim, S.U.; Kim, B.K.; Park, J.Y.; Kim, D.Y.; Ahn, S.H.; Park, Y.E.; Park, J.H.; Lee, Y.I.; Yun, H.R.; et al. Addition of tumor multiplicity improves the prognostic performance of the hepatoma arterial-embolization prognostic score. Liver Int. 2016, 36, 100-107. [CrossRef]

12. Mähringer-Kunz, A.; Wagner, F.; Hahn, F.; Weinmann, A.; Brodehl, S.; Schotten, S.; Hinrichs, J.B.; Düber, C.; Galle, P.R.; Pinto dos Santos, D.; et al. Predicting survival after transarterial chemoembolization for hepatocellular carcinoma using a neural network: A Pilot Study. Liver Int. 2020, 40, 694-703. [CrossRef]

13. Pinato, D.J.; Arizumi, T.; Jang, J.W.; Allara, E.; Suppiah, P.I.; Smirne, C.; Tait, P.; Pai, M.; Grossi, G.; Kim, Y.W.; et al. Combined sequential use of HAP and ART scores to predict survival outcome and treatment failure following chemoembolization in hepatocellular carcinoma: A multi-center comparative study. Oncotarget 2016, 7, 44705. [CrossRef]

14. Refolo, M.G.; Messa, C.; Guerra, V.; Carr, B.I.; D’Alessandro, R. Inflammatory mechanisms of HCC development. Cancers 2020, 12, 641. [CrossRef]

15. Buzby, G.P.; Mullen, J.L.; Matthews, D.C.; Hobbs, C.L.; Rosato, E.F. Prognostic nutritional index in gastrointestinal surgery. Am. J. Surg. 1980, 139, 160-167. [CrossRef]

16. Sun, K.; Chen, S.; Xu, J.; Li, G.; He, Y. The prognostic significance of the prognostic nutritional index in cancer: A systematic review and meta-analysis. J. Cancer Res. Clin. Oncol. 2014, 140, 1537-1549. [CrossRef]

17. Müller, L.; Hahn, F.; Mähringer-Kunz, A.; Stoehr, F.; Gairing, S.J.; Foerster, F.; Weinmann, A.; Galle, P.R.; Mittler, J.; Pinto dos Santos, D.; et al. Immunonutritive Scoring in Patients With Hepatocellular Carcinoma Undergoing Transarterial Chemoembolization: Prognostic Nutritional Index or Controlling Nutritional Status Score? Front. Oncol. 2021, 11, 2205. [CrossRef]

18. Rekik, S.; Guyot, E.; Bhais, M.; Ajavon, Y.; Grando, V.; Bourcier, V.; Nkontchou, G.; Nahon, P.; Sellier, N.; Seror, O.; et al. The CRP level and STATE score predict survival in cirrhotic patients with hepatocellular carcinoma treated by transarterial embolization. Dig. Liver Dis. 2016, 48, 1088-1092. [CrossRef]

19. Iida, H.; Tani, M.; Komeda, K.; Nomi, T.; Matsushima, H.; Tanaka, S.; Ueno, M.; Nakai, T.; Maehira, H.; Mori, H.; et al. Superiority of CRP-Albumin-Lymphocyte index (CALLY index) as a non-invasive prognostic biomarker after hepatectomy for hepatocellular carcinoma. HPB 2021, in press. [CrossRef]

20. Kloeckner, R.; Galle, P.R.; Bruix, J. Local and Regional Therapies for Hepatocellular Carcinoma. Hepatology 2021, 73, 137-149. [CrossRef]

21. Lammer, J.; Malagari, K.; Vogl, T.; Pilleul, F.; Denys, A.; Watkinson, A.; Pitton, M.; Sergent, G.; Pfammatter, T.; Terraz, S.; et al. Prospective Randomized Study of Doxorubicin-Eluting-Bead Embolization in the Treatment of Hepatocellular Carcinoma: Results of the PRECISION V Study. Cardiovasc. Interv. Radiol. 2010, 33, 41-52. [CrossRef]

22. Lencioni, R.; De Baere, T.; Burrel, M.; Caridi, J.G.; Lammer, J.; Malagari, K.; Martin, R.C.G.; O'Grady, E.; Real, M.I.; Vogl, T.J.; et al. Transcatheter treatment of hepatocellular carcinoma with Doxorubicin-loaded DC Bead (DEBDOX): Technical recommendations. Cardiovasc. Interv. Radiol. 2012, 35, 980-985. [CrossRef]

23. Weinmann, A.; Koch, S.; Niederle, I.M.; Schulze-Bergkamen, H.; König, J.; Hoppe-Lotichius, M.; Hansen, T.; Pitton, M.B.; Düber, C.; Otto, G.; et al. Trends in epidemiology, treatment, and survival of hepatocellular carcinoma patients between 1998 and 2009: An analysis of 1066 cases of a German HCC Registry. J. Clin. Gastroenterol. 2014, 48, 279-289. [CrossRef]

24. Huang, Z.-L.; Luo, J.; Chen, M.-S.; Li, J.-Q.; Shi, M. Blood neutrophil-to-lymphocyte ratio predicts survival in patients with unresectable hepatocellular carcinoma undergoing transarterial chemoembolization. J. Vasc. Interv. Radiol. 2011, 22, 702-709. [CrossRef]

25. Zheng, J.; Cai, J.; Li, H.; Zeng, K.; He, L.; Fu, H.; Zhang, J.; Chen, L.; Yao, J.; Zhang, Y.; et al. Neutrophil to lymphocyte ratio and platelet to lymphocyte ratio as prognostic predictors for hepatocellular carcinoma patients with various treatments: A meta-analysis and systematic review. Cell. Physiol. Biochem. 2017, 44, 967-981. [CrossRef]

26. Wang, B.; Huang, Y.; Lin, T. Prognostic impact of elevated pre-treatment systemic immune-inflammation index (SII) in hepatocellular carcinoma: A meta-analysis. Medicine 2020, 99, e18571. [CrossRef]

27. Chan, S.L.; Wong, L.-L.; Chan, K.-C.A.; Chow, C.; Tong, J.H.-M.; Yip, T.C.-F.; Wong, G.L.-H.; Chong, C.C.-N.; Liu, P.-H.; Chu, C.-M.; et al. Development of a novel inflammation-based index for hepatocellular carcinoma. Liver Cancer 2020, 9 , 167-181. [CrossRef] 
28. Yang, Z.; Zhang, J.; Lu, Y.; Xu, Q.; Tang, B.; Wang, Q.; Zhang, W.; Chen, S.; Lu, L.; Chen, X. Aspartate aminotransferase-lymphocyte ratio index and systemic immune-inflammation index predict overall survival in HBV-related hepatocellular carcinoma patients after transcatheter arterial chemoembolization. Oncotarget 2015, 6, 43090. [CrossRef]

29. Uno, H.; Cai, T.; Pencina, M.J.; D'Agostino, R.B.; Wei, L.-J. On the C-statistics for evaluating overall adequacy of risk prediction procedures with censored survival data. Stat. Med. 2011, 30, 1105-1117. [CrossRef]

30. Yu, L.-X.; Ling, Y.; Wang, H.-Y. Role of nonresolving inflammation in hepatocellular carcinoma development and progression. NPJ Precis. Oncol. 2018, 2, 6. [CrossRef] [PubMed]

31. El-Serag, H.B.; Rudolph, K.L. Hepatocellular Carcinoma: Epidemiology and Molecular Carcinogenesis. Gastroenterology 2007, 132, 2557-2576. [CrossRef] [PubMed]

32. Coussens, L.M.; Werb, Z. Inflammation and cancer. Nature 2002, 420, 860-867. [CrossRef] [PubMed]

33. He, C.-B.; Lin, X.-J. Inflammation scores predict the survival of patients with hepatocellular carcinoma who were treated with transarterial chemoembolization and recombinant human type-5 adenovirus H101. PLoS ONE 2017, 12, e0174769. [CrossRef]

34. Liu, Y.; Shi, M.; Chen, S.; Wan, W.; Shen, L.; Shen, B.; Qi, H.; Cao, F.; Wu, Y.; Huang, T.; et al. Intermediate stage hepatocellular carcinoma: Comparison of the value of inflammation-based scores in predicting progression-free survival of patients receiving transarterial chemoembolization. J. Cancer Res. Ther. 2021, 17, 740.

35. Li, S.; Feng, X.; Cao, G.; Wang, Q.; Wang, L. Prognostic significance of inflammatory indices in hepatocellular carcinoma treated with transarterial chemoembolization: A systematic review and meta-analysis. PLoS ONE 2020, 15, e0230879. [CrossRef]

36. Walsh, S.R.; Cook, E.J.; Goulder, F.; Justin, T.A.; Keeling, N.J. Neutrophil-lymphocyte ratio as a prognostic factor in colorectal cancer. J. Surg. Oncol. 2005, 91, 181-184. [CrossRef]

37. Smith, R.A.; Bosonnet, L.; Raraty, M.; Sutton, R.; Neoptolemos, J.P.; Campbell, F.; Ghaneh, P. Preoperative platelet-lymphocyte ratio is an independent significant prognostic marker in resected pancreatic ductal adenocarcinoma. Am. J. Surg. 2009, 197, 466-472. [CrossRef]

38. Hu, B.; Yang, X.-R.; Xu, Y.; Sun, Y.-F.; Sun, C.; Guo, W.; Zhang, X.; Wang, W.-M.; Qiu, S.-J.; Zhou, J.; et al. Systemic immuneinflammation index predicts prognosis of patients after curative resection for hepatocellular carcinoma. Clin. Cancer Res. 2014, 20, 6212-6222. [CrossRef]

39. Müller, L.; Stoehr, F.; Mähringer-Kunz, A.; Hahn, F.; Weinmann, A.; Kloeckner, R. Current Strategies to Identify Patients that Will Benefit from TACE Treatment and Future Directions a Practical Step-by-Step Guide. J. Hepatocell. Carcinoma 2021, 8, 403. [CrossRef]

40. Pugh, R.N.H.; Murray-Lyon, I.M.; Dawson, J.L.; Pietroni, M.C.; Williams, R. Transection of the oesophagus for bleeding oesophageal varices. Br. J. Surg. 1973, 60, 646-649. [CrossRef]

41. Johnson, P.J.; Berhane, S.; Kagebayashi, C.; Satomura, S.; Teng, M.; Reeves, H.L.; O’Beirne, J.; Fox, R.; Skowronska, A.; Palmer, D.; et al. Assessment of liver function in patients with hepatocellular carcinoma: A new evidence-based approach-The ALBI grade. J. Clin. Oncol. 2015, 33, 550. [CrossRef]

42. Pinato, D.J.; Sharma, R.; Allara, E.; Yen, C.; Arizumi, T.; Kubota, K.; Bettinger, D.; Jang, J.W.; Smirne, C.; Kim, Y.W.; et al. The ALBI grade provides objective hepatic reserve estimation across each BCLC stage of hepatocellular carcinoma. J. Hepatol. 2017, 66, 338-346. [CrossRef]

43. Vogeler, M.; Mohr, I.; Pfeiffenberger, J.; Sprengel, S.D.; Klauss, M.; Teufel, A.; Chang, D.-H.; Springfeld, C.; Longerich, T.; Merle, U.; et al. Applicability of scoring systems predicting outcome of transarterial chemoembolization for hepatocellular carcinoma. J. Cancer Res. Clin. Oncol. 2020, 146, 1033-1050. [CrossRef]

44. Zheng, Z.; Zhou, L.; Gao, S.; Yang, Z. Prognostic role of C-reactive protein in hepatocellular carcinoma: A systematic review and meta-analysis. Int. J. Med. Sci. 2013, 10, 653. [CrossRef]

45. Pan, J.; Chen, S.; Tian, G.; Jiang, T. Preoperative Albumin-Bilirubin Grade With Prognostic Nutritional Index Predicts the Outcome of Patients With Early-Stage Hepatocellular Carcinoma After Percutaneous Radiofrequency Ablation. Front. Med. 2020, 7, 584871. [CrossRef] [PubMed]

46. Müller, L.; Hahn, F.; Mähringer-Kunz, A.; Stoehr, F.; Gairing, S.J.; Foerster, F.; Weinmann, A.; Galle, P.R.; Mittler, J.; Pinto dos Santos, D.; et al. Refining Prognosis in Chemoembolization for Hepatocellular Carcinoma: Immunonutrition and Liver Function. Cancers 2021, 13, 3961. [CrossRef]

47. Fujiwara, N.; Nakagawa, H.; Kudo, Y.; Tateishi, R.; Taguri, M.; Watadani, T.; Nakagomi, R.; Kondo, M.; Nakatsuka, T.; Minami, T.; et al. Sarcopenia, intramuscular fat deposition, and visceral adiposity independently predict the outcomes of hepatocellular carcinoma. J. Hepatol. 2015, 63, 131-140. [CrossRef]

48. Imai, K.; Takai, K.; Watanabe, S.; Hanai, T.; Suetsugu, A.; Shiraki, M.; Shimizu, M. Sarcopenia Impairs Prognosis of Patients with Hepatocellular Carcinoma: The Role of Liver Functional Reserve and Tumor-Related Factors in Loss of Skeletal Muscle Volume. Nutrients 2017, 9, 1054. [CrossRef] 